\title{
Evaluation of the Level of Use of Motivational Factors in SMEs According to Selected Criteria
}

\author{
Iveta Kmecová ${ }^{1, *}$, Michal Tlustý ${ }^{1}$ \\ ${ }^{1}$ Institute of Technology and Business, Faculty of Corporate Strategy, Okružní 517/10, 37001 České Budějovice, Czech Republic
}

\begin{abstract}
The research presented in this contribution is an analysis of the level of use of motivational factors in small and medium-sized enterprises (SME) in terms of three criteria, as selected by the authors. The primary goal was to draw conclusions on the basis of the formulated hypotheses concerning the degree of use of motivational factors by SMEs. The literature review outlines the issue of work motivation and motivational factors. The practical part of the contribution presents the course of the specific calculations and the evaluation of the hypotheses. The primary data were obtained using the SAAPM questionnaire, which was created as part of a project by the Slovak Academic Association for Personnel Management (SAAPM). The data are evaluated using the one-sample t-test statistical method. The research sample consists of a total of 610 small and medium-sized enterprises (SMEs) in the Czech Republic.

Keywords: motivation; work motivation; motivational tools; small and medium enterprises (SMEs); onesample t-test
\end{abstract}

\section{Introduction}

The management of people's motivation and efficacy are strategic issues for all organizations that use human resources. Influencing work motivation is not only a matter for the human resources department of a company, but also for managers at all company management levels. Given the rising costs of labour, a successful company must fully use the potential of its employees and motivate them to deliver the best work performance possible. As the authors believe, the responsibility (read: mission) of every company should therefore be to provide its employees with a suitable incentive system that satisfies their employees and contributes to improving their performance and the achievement of the set goals.

\section{Theoretical background}

Currently, there are many motivational tools available to companies. In recent years, under the current economic conditions, companies have been forced to make changes within the business environment. Most companies have come to realize that the human factor is an important prerequisite for success and that reducing risks related to the human factor is important. This means that companies are increasingly striving to create a work environment that enables performance maximization and loss minimization [1].

It can be said that the issue of employee motivation, motivational tools, and their application in practice is a very widely discussed topic. According to [2], employee motivation should be seen as the mission of a company towards its stakeholders (i.e. towards its employees). Employees have different motivations for finding and keeping jobs [3]. This opinion is shared by [4], who claim that managers should know what motivational tool to apply towards employees because each employee is motivated by a different motivational factor. The success of an organization depends on motivated employees. To be able to perform everyday tasks, employees must feel motivated and satisfied [5]. It is therefore necessary, on the part of management, to create favourable conditions in companies and to have a suitable system of motivational tools in order to encourage work motivation and the engagement of employees. Internal benefits and motivational factors are used by multinational companies to establish long-term relationships [6]. According to [7], motivational factors are normally divided into five categories, whereby the best-known and most commonly used factors are financial or work-related. Within this context, companies try to create a pleasant working environment, make the work as interesting as possible, explain the added value of the work, etc.; these are mainly incentives. The third category covers social motivational factors. The fourth category consists of relational motivational factors, such as the atmosphere in the workplace, which is often reflected in the performance of teams of workers. The remaining category covers career motivational factors. According to $[8,9]$, adopting the right motivational strategy enables companies to benefit from the

\footnotetext{
* Corresponding author: kmecova @mail.vstecb.cz
} 
improved performance of a project team, which results in high customer satisfaction. [10] found that motivational factors differ according to position, age and gender. Managers should take the relationship between motivation and the age of employees into account and motivate their employees in different ways [11,12].

This contribution evaluates the level of use of motivational factors in small and medium-sized enterprises in the Czech Republic.

\section{Methodology}

The aim of this contribution is to use the one-sample t-test statistical method to compare the results of two parts of each established hypothesis and then to reject or confirm the whole hypothesis. The hypotheses relate to the level of use of motivational factors in companies.

\subsection{Data collection methods}

The data for this contribution were obtained via a questionnaire survey conducted among SMEs in the Czech Republic and from research activities (Industry 4.0) conducted in cooperation with the Slovak Academic Association for Personnel Management (SAAPM). In total, 615 companies participated in the research. Data collection took place in the first half of 2020 .

For the purposes of this contribution, the research sample was divided according to three criteria, namely: domestic or foreign ownership; industrial sector - manufacturing or logistics (these sectors were merged for the purposes of this contribution) or services; company size according to the number of employees (49 and fewer; 50 and more).

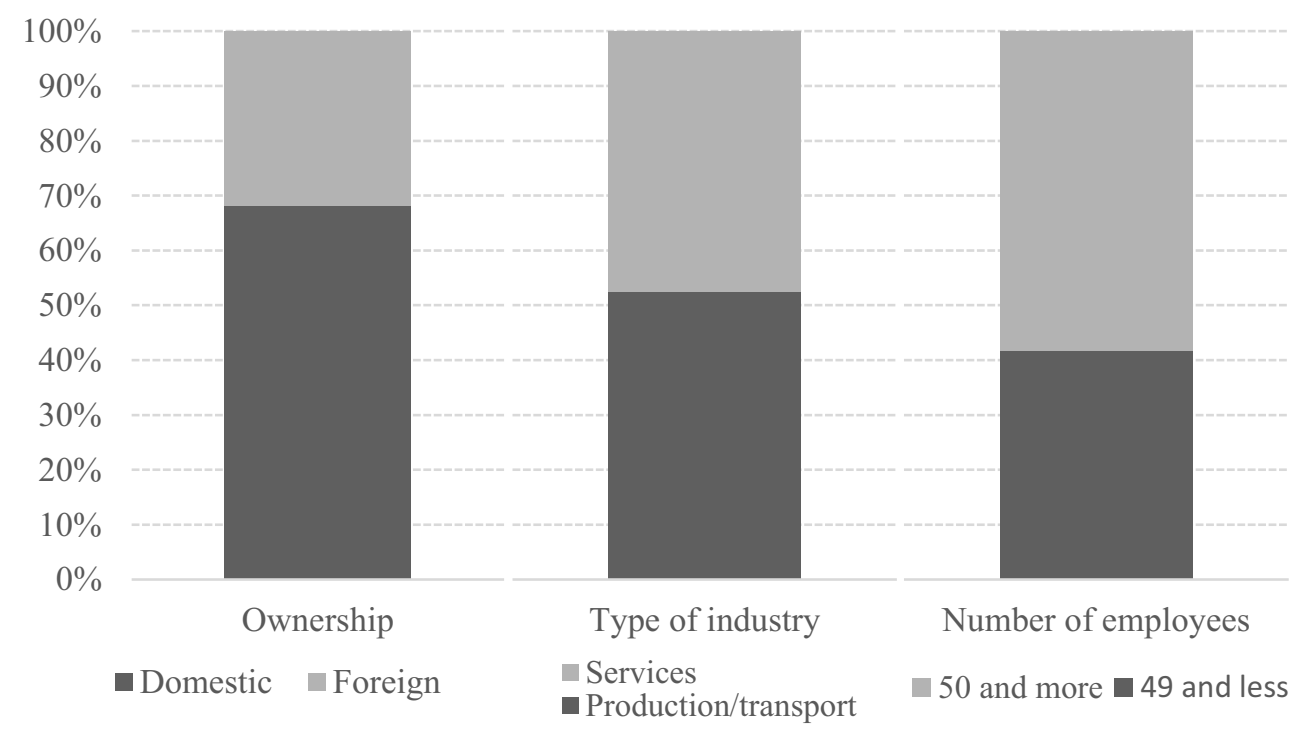

Figure 1. Division of companies

Source: Authors.

\subsection{Data evaluation methods}

To calculate the final value of the t-test, it is first necessary to develop auxiliary quantities. The first is the value of the arithmetic mean [13].

$$
\bar{x}=\frac{1}{n} *\left(x_{1}+x_{2}+x_{3}+\cdots+x_{n}\right)
$$

Where:

$\overline{\mathrm{x}}=$ arithmetic mean

$\mathrm{n}=$ number of sample values

$\mathrm{x}=$ individual file values

Another indicator is the sample variance [14].

$$
s^{2}=\frac{1}{n} \sum_{i=1}^{n}\left(x_{i}-\bar{x}\right)^{2}
$$


Where:

$\mathrm{s}^{2}=$ sampling variance

$\mathrm{x}_{\mathrm{i}}=$ individual values of the file

$\overline{\mathrm{x}}=$ arithmetic mean

The standard deviation can now be calculated [14].

$$
\sigma=\sqrt{s^{2}}
$$

Where:

$\sigma=$ standard deviation

$\mathrm{s}^{2}=$ file variance

If all the above-mentioned quantities are known, a one-sample t-test can be calculated.

$$
t=\frac{\bar{x}-\mu_{0}}{\sigma} \sqrt{n}
$$

Where:

$\mathrm{t}=$ value of one-sample $\mathrm{t}$-test

$\overline{\mathrm{x}}=$ arithmetic mean

$\mu_{0}=$ established null hypothesis

$\sigma=$ standard deviation

$\mathrm{n}=$ number of sample values

Finally, the resulting values of the t-test must be compared with the critical values from the tables available on the internet.

For the calculations, it is important to mention that the companies answered the questions using a scale of 1-5, where: $1=0 \% ; 2=25 \% ; 3=50 \% ; 4=75 \% ; 5=100 \%$. The percentage results are rounded to whole percentages.

\section{Results}

H1: Zero hypothesis: The level of use of motivational factors in both Czech-owned and foreign-owned companies is 75\% (comparison).

$$
\begin{gathered}
\bar{x}_{1}=\frac{1}{2080}(7836)=3.77=9 \% \\
\bar{x}_{2}=\frac{1}{970}(3755)=3.87=72 \% \\
s_{1}^{2}=\frac{1}{2080} *\left(x_{1}-3.77\right)^{2}+\left(x_{2}-3.77\right)^{2}+\cdots\left(x_{n}-3.77\right)^{2}=1.1 \\
s_{2}^{2}=\frac{1}{970} *\left(x_{1}-3.87\right)^{2}+\left(x_{2}-3.87\right)^{2}+\cdots\left(x_{n}-3.87\right)^{2}=0.9 \\
\sigma_{1}=\sqrt{1.1}=1.04 \\
\sigma_{2}=\sqrt{0.9}=0.95 \\
t_{1.1}=\frac{3.77-4}{1.04} \sqrt{2080}=|-10.09|=10.09 \\
t_{1.2}=\frac{3.87-4}{0.95} \sqrt{970}=|-4.26|=4.26
\end{gathered}
$$

The critical values can be obtained from the table of critical values in [16]. The critical value for both parts of the formulated hypothesis is 1.96 . Both t-test values are greater than the critical value set. As a result, both parts of the hypothesis can be rejected.

$$
\begin{aligned}
& \mathrm{p}-\text { value }_{1}=<2.2 \mathrm{e}-16 \\
& \mathrm{p} \text {-value } \\
& 2=2.684 \mathrm{e}-05
\end{aligned}
$$


Both p-values are clearly lower than 5\%, which also confirms the rejection of the hypothesis. The $95 \%$ interval for the first interval is $3.72-3.81$, while the interval for the second selection is $3.81-3.93$. The value for $75 \%$ ( 4 points) is not at this interval; this also confirms the rejection of the hypothesis. The results for both parts of the hypothesis are illustrated by means of the Gaussian curve (see Figures 2 and 3 below).

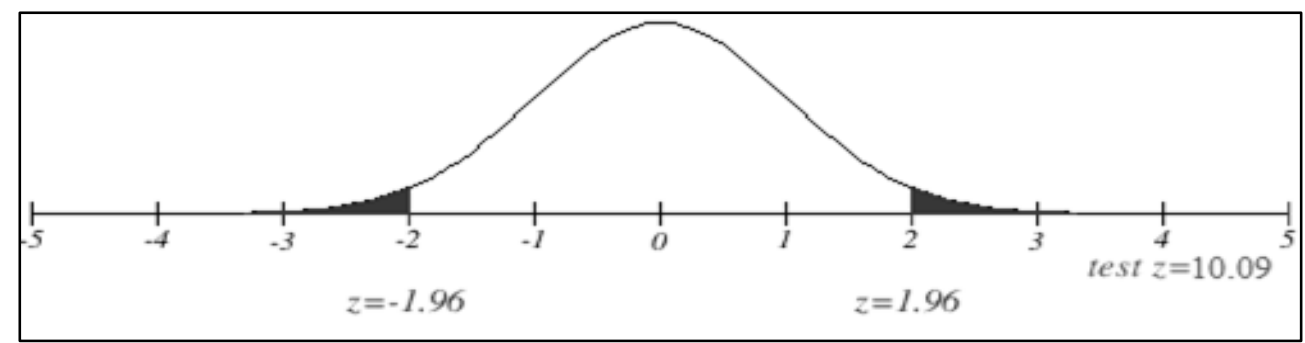

Figure 2. Gaussian curve of normal division $-\mathrm{H}_{1.1}$

Source: Authors, [15].

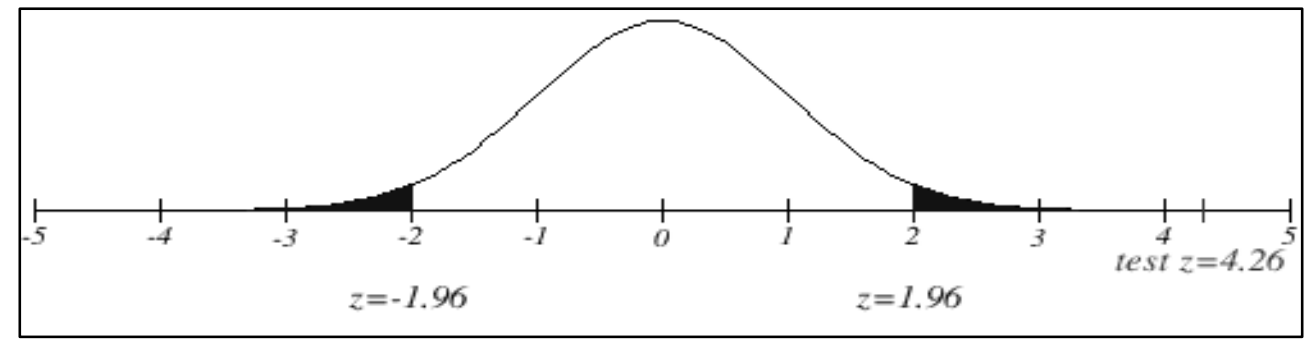

Figure 3. Gaussian curve of normal division $-\mathrm{H}_{1.2}$

Source: Authors, [15].

H2: Zero hypothesis: The level of use of motivational factors in companies operating in the manufacturing or logistics sector is $75 \%$, and for those operating in the services sector is $75 \%$ (comparison).

All the aforementioned calculations were carried out. It was subsequently possible to calculate the relevant t-test.

$$
\begin{gathered}
t_{2.1}=\frac{3.78-4}{1.03} \sqrt{1435}=|-8.09|=8.09 \\
t_{2.2}=\frac{3.82-4}{0.99} \sqrt{1295}=|-6.54|=6.54
\end{gathered}
$$

The table of critical values for the t-distribution in [16] shows that the critical value for both groups of companies is 1.96. The t-test values are clearly greater than the critical value. As a result, the hypothesis cannot be confirmed at a $95 \%$ significance level. The hypothesis is therefore rejected.

$$
\begin{aligned}
\text { p-value } & =4.663 \mathrm{e}-15 \\
\text { p-value } & =5.516 \mathrm{e}-11
\end{aligned}
$$

The comparison of both p-values confirmed the rejection of this hypothesis. Both p-values are clearly lower than 5\%; the hypothesis is therefore rejected. This statement can be confirmed also by means of a 95\% quartile. The quartile for the first part of the hypothesis, i.e. for those companies in the manufacturing and logistics sectors, is $3.73-3.84$, and for the second part of the hypothesis, i.e. for those companies in the services sector, is $3.76-3.87$. The obtained value (4) is clearly not in either of the quartiles; rejection of the hypothesis is therefore confirmed.

H3: Zero hypothesis: The level of use of motivational factors in small companies (49 or fewer employees) is 75\%, and in larger companies (50 or more employees) is $75 \%$ (comparison).

$$
\begin{aligned}
& t_{3.1}=\frac{3.74-4}{1.04} \sqrt{1275}=|-8.93|=8.93 \\
& t_{3.2}=\frac{3.84-4}{1} \sqrt{1776}=|-6.74|=6.74
\end{aligned}
$$

Even in this case, the relevant critical value [16] is 1.96. Both t-test values are clearly higher than the critical value specified above; it is therefore recommended to reject this hypothesis.

$$
\begin{aligned}
& \text { p-value }{ }_{3.1}=<2.2 \mathrm{e}-16 \\
& \text { p-value } \\
& 3.2=8.325 \mathrm{e}-11
\end{aligned}
$$


Both p-values are lower than 5\%, which confirms the rejection of the hypothesis. The $95 \%$ quartile for the first part of the hypothesis, i.e. for those companies with 49 or fewer employees, is $3.68-3.8$, and for the second part of the hypothesis, i.e. for those companies with 50 or more employees, is $3.8-3.89$. The value of $4(75 \%)$ does not fall within any of the quartiles; rejection of the hypothesis was therefore correct.

H4: Zero hypothesis: The level of use of motivational factors now and planned in the future is 75\% (comparison).

$$
\begin{gathered}
t_{4.1}=\frac{3.8-4}{1.02} \sqrt{3050}=|-10.83|=10.83 \\
t_{4.2}=\frac{4.36-4}{0.84} \sqrt{3050}=23.67
\end{gathered}
$$

The critical values [16] for both categories are identical - 1.96. Both resulting values of the t-tests are higher than the critical values; both parts of the hypothesis can therefore be rejected.

$$
\begin{aligned}
& \text { p-value }_{4.1}=<2.2 \mathrm{e}-16 \\
& \text { p-value }_{4.2}=<2.2 \mathrm{e}-16
\end{aligned}
$$

Both p-values are lower than 5\%, which also contributes to the rejection of the hypothesis. This is confirmed by the analysis of the $95 \%$ quartiles. The $95 \%$ quartile for the current use of motivational factors is $3.76-3.84$, while for planned use in the future is $4.33-4.39$. The tested value of 4 does not fall within the quartiles; the hypothesis can therefore be decidedly rejected.

\section{Discussion}

The results of all hypotheses are presented in Table 1.

Table 1. Summary of results

\begin{tabular}{|c|c|c|c|}
\hline Hypothesis & t-test values & Critical values & Result \\
\hline $\mathrm{H}_{1}$ & $10.09 ; 4.26$ & $1.96 ; 1.96$ & Hypothesis rejected \\
\hline $\mathrm{H}_{2}$ & $8.09 ; 6.54$ & $1.96 ; 1.96$ & Hypothesis rejected \\
\hline $\mathrm{H}_{3}$ & $8.93 ; 6.74$ & $1.96 ; 1.96$ & Hypothesis rejected \\
\hline $\mathrm{H}_{4}$ & $10.83 ; 23.67$ & $1.96 ; 1.96$ & Hypothesis rejected \\
\hline
\end{tabular}

Source: Authors.

H1: Zero hypothesis: The level of use of motivational factors in both Czech-owned and foreign-owned companies is $75 \%$ (comparison).

The first hypothesis examined whether the level of use of motivational factors in companies is affected by the fact that a company is Czech- or foreign-owned, and whether the level is about 75\%. The results show that neither of the parts of the hypothesis confirm that the level of use of motivational factors is about $75 \%$. Specifically, for Czech-owned this was about 69 , and for foreign-owned companies about $72 \%$. It can therefore be said that although the hypothesis was rejected, the use of motivational factors is more common in foreign-owned companies; however, the difference is not significant.

H2: Zero hypothesis: The level of use of motivational factors in companies operating in the manufacturing or logistics sector is $75 \%$, and for those operating in the services sector is $75 \%$ (comparison)

For the verification of the second hypothesis, the companies were divided according to the industrial sector in which they operate. The first group includes those companies operating in the manufacturing or logistics sectors, the second group includes those companies operating in the services sector. Moreover, it was examined whether the level of use of motivational factors is close to $75 \%$. The results indicate that there are no significant differences in the level of use of motivational factors according to the indicated industrial sectors. The values for both categories was about $70 \%$. The hypothesis was therefore rejected.

H3: Zero hypothesis: The level of use of motivational factors in small companies (49 or fewer employees) is 75\%, and in larger companies (50 or more employees) is $75 \%$ (comparison).

This hypothesis dealt with the influence of the number of employees on the level of use of motivational factors in companies, specifically that these values achieved $75 \%$. The companies were divided into two categories: companies with 49 or fewer employees; and companies with 50 or more employees. It was found that the values for both categories were about $70 \%$; the hypothesis was therefore rejected.

H4: Zero hypothesis: The level of use of motivational factors now and planned in the future is $75 \%$ (comparison). 
The last formulated hypothesis examined the satisfaction of the companies with their current level of use of motivational factors, whether they plan to increase or reduce their use thereof, and whether the level of use is close to $75 \%$. The first part of the hypothesis, concerning the current situation, was rejected; it was found that the level of use of motivational factors in companies is currently about $70 \%$. The second part of the hypothesis was also rejected; however, in this case, the results indicated a level of $84 \%$. This indicates that the companies are not satisfied with their current level of use of motivational factors and that they are planning significant improvements for the future.

\section{Conclusion}

In conclusion, the companies were subject to statistical analysis by means of a one-sample t-test. Firstly, the companies were divided into several categories according to predetermined criteria, namely: domestic or foreign ownership; industrial sector - manufacturing or logistics (these sectors were merged for the purposes of this contribution) or services; company size according to the number of employees (49 and fewer; 50 and more), on the basis of which hypotheses were subsequently formulated. The fourth hypothesis examined whether there are any differences in the current and planned level of use motivational factors. Secondly, auxiliary variables were calculated, such as arithmetic mean, variance, standard deviation, etc., for each hypothesis. Thirdly, specific t-test values were calculated and, on the basis of tables of critical values, a decision made as to whether to confirm or reject the hypothesis. The decision to reject a hypothesis was confirmed by means of calculated p-values and 95\% quartiles. It was found that the values for the level of use of motivational factors did not achieve $75 \%$, whereby neither differences in ownership, industrial sector nor company size proving to have a significant impact on these values. However, the last hypothesis provided interesting results. It was found that the current level of use of motivational factors in companies is about $70 \%$, with companies appearing to be dissatisfied with this value and planning significant improvements (up to 84\%) for the future.

\section{Acknowledgement}

This contribution is an output created within the project 8110-002 of the Internal Grant Competition called Innovation for the study "Human Resource Management".

The contribution uses data obtained from the research activities of the Slovak Academic Association for Personnel Management (SAAPM).

\section{References}

1. F. L. Cooke, R. Schuler, A. Varma, Human resource management research and practice in Asia: Past, present and future. Human Resource Management Review. 30(4) (2020)

2. M. Bastons, M. Mas, C. Rey, Pro-stakeholders motivation: Uncovering a new source of motivation for business companies. Journal of Management and Organization. 23, 621-632 (2017)

3. N. A. Muslim, D. Dean, D. Cohen, Employee Job Search Motivation Factors: An evidence from Electricity Provider Company in Malaysia. Procedia Economics and Finance. 35, 532-540 (2016)

4. J. Faletar, D. Jelačić, L. Oblak, Comparison of motivation factors in two wood processing companies. Acta Silvae et Ligni. 111, 1-11 (2016)

5. R. Alamelu, R. Amudha, R. Nalini, L. C. S. Motha, I. Bahavathi, Measure of motivation practices - An employee's insight. International Journal of Economic Research. 14, 409-415 (2017)

6. S. Bhattacheryay, Multinational enterprises motivational factors in capitalizing emerging market opportunities and preparedness of India. Journal of Financial Economic Policy. In print (2020)

7. M. Yunus, E. Yusuf Iis, M. Adam, H. Sofyan, Does motivation mediate the effects of employee staff empowerment, talent, working environment, and career development on staff performance? Quality - Access to Success. 21, 91-96 (2020)

8. M. M. Uthappa, A. N. Santosh Kumar, Impact of motivational factors on project team performance. Test Engineering and Management. 83, 5168-5176 (2020)

9. K. C. Diwas, Worker productivity in operations management. Foundations and Trends in Technology, Information and Operations Management. 13, 151-249 (2020)

10. S. Lorincová, P. Štarchoň, D. Weberová, M. Hitka, M. Lipoldová, Employee motivation as a tool to achieve sustainability of business processes. Sustainability. 11 (2019)

11. L. Ližbetinová, M. Hitka, C. Li, Z. Caha. Motivation of employees of transport and logistics companies in the Czech Republic and in a Selected Region of the PRC. MATEC Web of Conferences. 134 (2017) 
12. S. Lorincová, M. Hitka, P. Štarchoň, K. Stachová, Strategic instrument for sustainability of human resource management in small and medium-sized enterprises using management data. Sustainability. 10 (2018)

13. M. Budíková, M. Králová, B. Maroš, Průvodce základními statistickými metodami [Guide to basic statistical methods]. Praha: Grada Publishing. (2010)

14. J. Neubaeur, M. Sedlačík, O. Kříž, Základy statistiky - Aplikace v technických a ekonomických oborech [Basics of statistics - Applications in technical and economic fields]. Praha: Grada Publishing (2016)

15. Imathas. Gaussian curve creation tool. [online]. Available at: http://www.imathas.com/stattools/norm.html (2020)

16. Lekopis. Table of critical values of t-distribution. [online]. Available at: http://www.lekopis.cz/Kap_5_3_8_2.htm (2020) 